\title{
Correction to: Introduction to the Special Issue: Advances in Psychogastroenterology
}

\section{Andrea Bradford ${ }^{1}[$ ]}

Published online: 14 August 2020

○) Springer Science+Business Media, LLC, part of Springer Nature 2020

\section{Correction to: \\ Journal of Clinical Psychology in Medical Settings https://doi.org/10.1007/s10880-020-09735-3}

Due to a publishing error, an article referred to here that was intended for the special section Advances in Gastroenterology was inadvertently published in the previous issue, Volume 27, Issue 2.

Wabich, J., Bellaguarda, E., Joyce, C. et al. (2020). Disordered eating, body dissatisfaction, and psychological distress in patients with inflammatory bowel disease (IBD). Journal of Clinical Psychology in Medical Settings, 27, 310-317. https://doi.org/10.1007/s10880-020-09710-y.
Publisher's Note Springer Nature remains neutral with regard to jurisdictional claims in published maps and institutional affiliations.

The original article can be found online at https://doi.org/10.1007/ s10880-020-09735-3.

Andrea Bradford andrea.bradford@bcm.edu

1 Department of Medicine, Section of Gastroenterology and Hepatology, and Menninger Department of Psychiatry and Behavioral Sciences, Baylor College of Medicine, 7200 Cambridge Street Suite 8A, Houston, TX 77030, USA 